\title{
SISTEMA NACIONAL DE INVERSIÓN PÚBLICA
}

\author{
Rodrigo Díaz Inverso*
}

\begin{abstract}
RESUMEN. La inversión pública constituye una herramienta fundamental de política económica para cualquier Estado. A efectos de encauzarla, ordenarla y optimizarla se creó el Sistema Nacional de Inversión Público, el cual es analizado en sus ámbitos objetivo, concepto de inversión pública y subjetivo, órganos y sistemas orgánicos incorporados, su constitucionalidad en virtud de los regímenes autonómicos y sus impactos en distintos temas como la competencia de la Oficina de Planeamiento y Presupuesto y la normativa constitucional en materia de presupuestos públicos, entre otros.
\end{abstract}

PALABRAS CLAVE. Inversión pública. Hacienda pública. Oficina de Planeamiento y Presupuesto. Control presupuestal. Constitución.

ABSTRACT. Public investment is a fundamental tool of economic policy for any state. In order to steer, order and optimize it, the National System of Public Investment was created, which is analyzed in its objective, public investment concept, and subjective (incorporated agencies scopes, its constitutionality due to autonomous regimes and its effects on different issues such as the competence of the Office of Planning and Budget and constitutional provisions on public budgets, among others.

KEY WORDS. Public investment. Public Treasury. Office of Planning and Budget. Budget control. Constitution.

\section{INTRODUCCIÓN.}

Dentro de una economía existen ciclos de crecimiento, empleo y aumentos de salario, seguidos de recesión, desempleo y baja de salario que están determinados exclusivamente

* Doctor en Derecho y Ciencias Sociales por la Universidad de la República. Aspirante a Profesor Adscripto en Derecho Administrativo por la misma Universidad. Correo electrónico: rodrigodiazinverso@hotmail.com

** Abreviaturas: Comisión de Inversiones y Desarrollo (CIDE); Conformidad Técnica (CT); Dictamen Técnico Favorable (DTF); Oficina de Planeamiento y Presupuesto (OPP); Sistema Nacional de Inversión Pública (SNIP); Texto Ordenado de Inversiones (TOI). 
por la demanda. ${ }^{1}$ Integrando la demanda se encuentra el gasto público, que constituye un componente susceptible de manejo deliberado por parte del Estado, para poder contrarrestar y prevenir las crisis económicas. Dentro del gasto público, encontraremos la inversión pública.

Basta ver los números macroeconómicos del Uruguay en la última década para darse cuenta de la importancia que la inversión pública tiene en nuestra economía, siendo durante algunos períodos de tiempo superior a la de origen privado (por ejemplo, durante los años 2007 a 2010, y 2015 a 2016). ${ }^{2}$

En general desde las ciencias económicas se sostiene que existe inversión cuando se produce un nuevo capital real en la sociedad (equipos, edificios, existencias de mercaderías, entre otros). Por otro lado, la inversión suele ser considerada "pública" cuando proviene del Estado. Así, DELPIAZZO sostiene que "[s]iguiendo un criterio económico tendiente a mostrar los efectos de la intervención del Estado en la economía, se dice que los gastos de funcionamiento (o corrientes) son aquellos que no alteran la capacidad instalada de la economía así como los destinados a consumos cuyos beneficios se agotan de una sola vez, mientras que los gastos de inversión (o de capital) son aquellos que aumentan la capacidad instalada de la economía o cuyos beneficios son duraderos o persisten en el mediano y largo plazo."3 Por tanto, dentro de ese concepto de gasto público, encontraríamos a los gastos corrientes y a la inversión, radicando la diferencia en si aumenta o no la capacidad instalada de una economía o si se constituyen beneficios de largo plazo.

\section{a. La inversión en la Constitución}

Nuestra Constitución refiere a las inversiones en forma fragmentada y con distinto alcance. Así, en el artículo $45^{4}$ refiere a uno de los dos géneros de inversión: la inversión privada, como contrapuesta a la inversión estatal. Por su parte, en la medida en que en la hipótesis regulada por dicho artículo los recursos se destinan a beneficios de duración en el tiempo (viviendas), se trataría propiamente de una inversión en términos económicos.

En el artículo $50^{5}$ la inversión no es mencionada en relación al sujeto que la realiza (público o privado) sino a partir de su finalidad: promover actividades productivas cuyo destino sea la exportación o la sustitución de productos importados. Aparece la inversión ligada a un objetivo de política sectorial bien definido, sin importar si es de origen público o privado. Se trata claramente de una inversión en sentido estricto, en tanto impacta en la capacidad de la economía de producir bienes y servicios, y comprende tanto a la de origen estatal como no estatal.

1 Cfr. BLANCO, Andrés. Estudios críticos sobre Finanzas Públicas y Derecho Tributario. Montevideo, Fundación de Cultura Universitaria, 2013, p. 10

2 Datos disponibles en: https://www.mef.gub.uy/10473/8/areas/inversion.html. Fecha de consulta: 2 de febrero de 2019.

3 DELPIAZZO, Carlos E. "Régimen de inversiones" en DELPIAZZO, Carlos E. (Coordinador), Comentarios al TOCAF sobre la Hacienda Pública, Montevideo, Universidad de Montevideo, 2012, p. 100.

${ }_{4}$ Artículo 45.- Todo habitante de la República tiene derecho a gozar de vivienda decorosa. La ley propenderá a asegurar la vivienda higiénica y económica, facilitando su adquisición y estimulando la inversión de capitales privados para ese fin.

5 Artículo 50.- El Estado orientará el comercio exterior de la República protegiendo las actividades productivas cuyo destino sea la exportación o que reemplacen bienes de importación. La ley promoverá las inversiones destinadas a este fin, y encauzará preferentemente con este destino el ahorro público. 
En el artículo 85 numeral $4^{6}$ la inversión es de fuente estatal, en la medida en que la vincula a su actividad financiera: el Estado recauda "contribuciones" (como sinónimo de tributos) y las "invierte" (en obras, en servicios, etc.). En línea similar se encuentra el artículo 168 numeral $19^{7}$ (en donde la inversión es de carácter estatal y vinculada a la dinámica presupuestal) y el artículo 214 literal $\mathrm{B}^{8}$ (que diferencia dos rubros que integran el presupuesto "los gastos corrientes" y "las inversiones"). Es decir que, en términos constitucionales la inversión se opondría al gasto corriente, entendido éste como -según ya dijéramos- aquellos que no aumentan la capacidad instalada de la economía o cuyos beneficios se agotan de una sola vez.

El artículo $302^{9}$ también recoge una forma de inversión pública-estatal aunque más restringida en cuanto al sujeto activo (Gobierno Departamental). Incluye un adjetivo ("remuneradora") cuyo significado no es sencillo de encontrar en la literatura. Podría referir a la cualidad de la inversión de aumentar la capacidad de producir bienes o servicios, lo cual -como vimos- ya estaría incorporado al concepto de inversión a secas.

Finalmente, la expresión "Inversiones” también está presente en la Disposición Transitoria O, que refiere a la Oficina de Planeamiento y Presupuesto (OPP) y le asigna el carácter de sucesora de la Comisión de Inversiones y Desarrollo (CIDE). ${ }^{10}$

Como vemos entonces, nuestra Constitución utiliza el término inversión alineado con el sentido normal que se le atribuye. Y si bien no utiliza la voz "inversión pública”, surge implícitamente de aquellos casos en que refiere a fondos que provienen del Estado.

\section{b. Texto Ordenando de Inversiones (TOI)}

A nivel infraconstitucional, podemos citar la definición de inversión que recoge el artículo 1 del Texto Ordenado de Inversiones (TOI) ${ }^{11}$, que establece que "se considera

6 Artículo 85.- $4^{\circ}$ ) Establecer las contribuciones necesarias para cubrir los presupuestos, su distribución, el orden de su recaudación e inversión, y suprimir, modificar o aumentar las existentes.

7 Artículo 168.- 19) Preparar y presentar a la Asamblea General los presupuestos, de acuerdo a lo establecido en la Sección XIV, y dar cuenta instruida de la inversión hecha de los anteriores.

8 Artículo 214.- El Presupuesto Nacional se proyectará y aprobará con una estructura que contendrá: A) Los gastos corrientes e inversiones del Estado distribuidos en cada Inciso por programa. (...) El Poder Ejecutivo dentro de los seis meses de vencido el ejercicio anual, que coincidirá con el año civil, presentará al Poder Legislativo la Rendición de Cuentas y el Balance de Ejecución Presupuestal correspondiente a dicho ejercicio, pudiendo proponer las modificaciones que estime indispensables al monto global de gastos, inversiones y sueldos o recursos y efectuar creaciones, supresiones $y$ modificaciones de programas por razones debidamente justificadas.

9 Artículo 302.- Todo superávit deberá ser integramente aplicado a amortizaciones extraordinarias de las obligaciones departamentales. Si dichas obligaciones no existiesen, se aplicará a la ejecución de obras públicas o inversiones remuneradoras, debiendo ser adoptada la resolución por la Junta Departamental, a propuesta del Intendente y previo informe del Tribunal de Cuentas.

10 De acuerdo a su decreto de creación de 27 de enero de 1960, la CIDE tenía entre sus cometidos los de "formular planes orgánicos de desarrollo económico, proyectar y buscar su financiación interna y externa, coordinar toda labor tendiente a aumentar la productividad nacional y vigilar la puesta en práctica de los planes que se apruebe" (art. 2).

11 El texto ordenado actual fue aprobado por Decreto $\mathrm{N}^{\circ} 123 / 012$ que sustituye al anterior, aprobado por Decreto $\mathrm{N}^{\circ}$ 342/997. Por su parte, el decreto comete a la OPP (art.3) la actualización del mencionado texto, estando actualmente vigente la versión que fuera aprobada por dicho órgano el 23 de diciembre de 2016. El artículo 1, encuentra su fuente en el Artículo 78 de la Ley $\mathrm{N}^{\circ} 15.809$, de 8 de abril de 1986 , sustituido por el artículo 48 de la Ley $\mathrm{N}^{\circ} 17.296$, de 21 de febrero de 2001 , sustituido a su vez por el artículo 
inversión pública a los efectos presupuestales, la aplicación de recursos a todo tipo de bienes y actividades que incrementen el patrimonio físico de los organismos que integran el Presupuesto Nacional, con el fin de ampliar, mejorar, modernizar, reponer o reconstruir la capacidad productora de bienes o prestadora de servicios. Incluye, asimismo, los pagos sin contraprestación cuyo objeto sea que los perceptores adquieran activos de capital. Esta definición comprende los estudios previos de los proyectos a ser ejecutados."

Dado que es concepto de inversión pública aplicable a los efectos presupuestales, puede considerarse interpretativo del artículo 214 de la Carta. Este concepto exige que: (i) los recursos sean aplicados a bienes o actividades; (ii) que aumenten el patrimonio físico de los organismos del Presupuesto Nacional, por lo que excluye por ejemplo los recursos destinados a capacitación de funcionarios, o la prestación de servicios que no supongan dicho aumento; (iii) ese aumento debe estar ligado al mejoramiento de la capacidad productora de bienes o prestadora de servicios.

Se trata de un concepto de inversión acorde al tradicional, comprendiendo también las transferencias presupuestales a terceros que lo reciban para adquirir activos de capital; en tal caso, a pesar de que no es la Administración quien directamente aumenta su patrimonio, el hecho de que el destinatario de la partida sí lo haga, lo hace incluir dentro del concepto de inversión pública, ${ }^{12}$ independientemente de que no integre el Estado-aparato.

\section{La inversión pública en el marco del Sistema Nacional de Inversión Pública.}

\section{a. Breve introducción al SNIP}

El Sistema Nacional de Inversión Pública (SNIP) fue creado por los artículos 23 a 25 de la Ley $\mathrm{N}^{\circ} 18.996$ de 7 de noviembre de 2012, donde es definido como "el conjunto de normas y procedimientos establecidos con el objeto de ordenar y orientar el proceso de inversión pública en el país, sin perjuicio de las autonomías y competencias constitucionales, a fin de optimizar la asignación de recursos públicos con ajuste a las políticas sectoriales nacionales diseñadas por el Poder Ejecutivo."El concepto de inversión pública en el marco del SNIP no está definido en la ley, pero sí en su decreto reglamentario $\mathrm{N}^{\circ} 231$ / 015 de 31 de agosto de 2015.

El SNIP prevé, esencialmente, dos instancias de control a los proyectos de inversión pública: una en la etapa de pre-inversión, destinado a la incorporación o no del proyecto a la etapa presupuestal o de financiamiento, y uno posterior, previo a su ejecución. En la

73 de la Ley $\mathrm{N}^{\circ} 18.719$ de 27 de diciembre de 2010. Se pueden ver los antecedentes del concepto legal de inversión en: DELPIAZZO, Carlos E. "Promoción y captación de la inversión privada en el sector público" en ROTONDO, Felipe (Coordinador), Regulación de la actividad privada, Montevideo, Fundación de Cultura Universitaria, 2015, p. 101-103. Decreto-ley 14.867, ley 15809 (art. 78) y Ley Nº 17.296 (art. 48). También en VIDAL, Martha. La gestión financiera del Estado, Montevideo, Fundación de Cultura Universitaria, 2015, p. 188-191.

12 Las leyes de presupuesto y rendición de cuenta suelen contener partidas destinadas a entidades privadas no estatales que realizan actividades que se consideran socialmente valiosas y a las cuales el Estado pretender fomentar con ayuda económica. Dichas transferencias, en la medida en que sean destinadas por su beneficiario a la adquisición de patrimonio físico, ingresarían dentro del concepto de inversión pública. 
primera etapa se emitirá la "Conformidad Técnica" (CT); en la segunda, un "Dictamen Técnico Favorable” (DTF); de esta forma, la CT constituye un requisito para que el proyecto pueda ser incorporado al presupuesto (aunque no garantiza su incorporación); mientras que el DTF será el aval requerido para la ejecución. ${ }^{13}$

\section{b. Ámbito de aplicación}

Desde el punto de vista subjetivo, la calificación de inversión pública del SNIP exige que sea realizada por cualquiera de las "instituciones" del artículo 24, a saber:

a) “...órganos y organismos comprendidos en el Presupuesto Nacional”. La interpretación en este caso comprende a los sistemas orgánicos y personas jurídicas públicas estatales cuyo presupuesto es aprobado con cadencia quinquenal y a través de la denominada Ley de Presupuesto. ${ }^{14}$ Resulta discutible si alcanza a los órganos del Poder Legislativo, a cuyos efectos debería determinarse si pueden considerarse o no integrantes del Presupuesto Nacional; desde el punto de vista formal, sus presupuestos se aprueban por acto administrativo y no por la ley de presupuesto quinquenal, por lo que no parecen ser "integrantes" de dicho presupuesto, excepto que entendamos que su "incorporación” por el artículo 108 de la Constitución determina que lo integren. ${ }^{15}$

b) “...entes autónomos y servicios descentralizados del dominio industrial y comercial del Estado...”. En este caso la referencia no requiere mayores puntualizaciones, siendo los previstos en el artículo 185 de la Carta.

c) “...Gobiernos Departamentales...."16 Al no incluirse una diferenciación entre el sistema orgánico que ejerce primordialmente función administrativa (Intendencia) y el que ejerce primordialmente función legislativa (Junta Departamental), ambos quedan comprendidos, en tanto forman parte de la persona pública Gobierno Departamental. A efectos del SNIP, no es relevante la diferencia entre el presupues-

13 Puede consultarse en mayor detalle el procedimiento en: SOLER, Graciela. "Contralor de organismos estatales y no estatales a través del SNIP” en ROTONDO, Felipe (Coordinador), Control estatal sobre la entidades públicas y las instrumentales de derecho privado, Montevideo, Fundación de Cultura Universitaria, 2017, p. 41-51.

14 Poder Ejecutivo, Poder Judicial, Corte Electoral, Tribunal de Cuentas, Tribunal de lo Contencioso Administrativo (hasta aquí, todos sistemas orgánicos integrantes del Estado persona pública mayor), los Entes Autónomos y Servicios Descentralizados no industriales ni comerciales (Universidad de la República, Administración Nacional de Educación Pública, Universidad Tecnológica, Instituto Uruguayo de Meteorología, Instituto del Niño y el Adolescente del Uruguay, Instituto Nacional de Inclusión Social Adolescente, la Administración de los Servicios de Salud del Estado, la Junta de Transparencia y Ética Pública, la Fiscalía General de la Nación).

15 Artículo 108.- Cada Cámara aprobará, dentro de los doce primeros meses de cada Legislatura, sus presupuestos por tres quintos de votos del total de sus componentes y lo comunicará al Poder Ejecutivo para que los incluya en el Presupuesto Nacional.

16 Elaborado y aprobado por ella misma, de acuerdo al artículo 273 numeral 6.

Cabe destacar que el propio artículo 24 establece que, en relación a los Gobiernos Departamentales, la reglamentación será elaborada en el marco de la de la Comisión Sectorial prevista en el inciso quinto, literal b) del artículo 230 de la Constitución de la República, en la cual ellos se encuentra representados. Por tal motivo, el Decreto $N^{\circ} 231 / 015$ no resulta de aplicación a los Gobiernos Departamentales. Ello nos lleva a sostener que, a la fecha, y ante la ausencia de dicha reglamentación, los Gobiernos Departamentales no quedan aun comprendidos por el SNIP. 
to departamental ${ }^{17}$ y el presupuesto de la Junta Departamental, ${ }^{18}$ quedando ambos comprendidos.

d) “. . personas públicas no estatales...”. Esta noción no presenta mayores dificultades, sin perjuicio de las dudas que puedan plantearse en relación a la pertenencia o no a la categoría de ciertas personas jurídicas.

e) “...sociedades de economía mixta, tanto las regidas por el derecho público como por el derecho privado..."; son entidades creadas al amparo del artículo 188 inciso primero y segundo (de derecho público) y tercero y cuarto (de derecho privado).

f) “...entidades privadas de propiedad estatal, cualquiera sea su naturaleza jurídica." Esta disposición hace ingresar al SNIP a todas las sociedades comerciales cuya titularidad sea de una persona pública estatal, conocidas como entes instrumentales de la Administración, y que han sido definidas como "aquellas personas juridicas constituidas o creadas por una administración pública, dotadas de personalidad jurídica propia, y a las que se encomienda la gestión de alguna o algunas de las competencias de titularidad del ente matriz." ${ }^{19}$ La utilización del término "entidad" (en lugar del de sociedad), permite incluir también a las de carácter no comercial como las fundaciones constituidas por entes estatale ${ }^{20}$, e incluso a los fideicomisos. En el caso de las primeras (las fundaciones), no existe inconveniente, en tanto son personas jurídicas ${ }^{21}$; en relación a los segundos (fideicomisos) dado que no se encuentran dotados de personería jurídica sino que son patrimonios de afectación, la situación deviene discutible. De todas formas, la utilización del polisémico término "entidad”, y las pretensiones de generalidad del SNIP, permiten postular la interpretación amplia respecto de su alcance, quedando también comprendidos los fideicomisos o patrimonios de afectación. Cabe destacar que la disposición normativa no fija qué porcentaje de las acciones, participaciones o cuotas sociales deben estar en propiedad del Estado, por lo que debe entenderse que no establece un umbral mínimo; basta con que el Estado (en sentido amplio) sea propietario de alguna cuota parte del capital para que la entidad quede alcanzada por el SNIP.

Como puede apreciarse, la inversión pública a que refiere el SNIP no es sinónimo de inversión estatal, ni tampoco se limita a las entidades regidas por el derecho público. Con esto el SNIP recogería las ideas de DELPIAZZO en torno a la necesaria "interpretación evolutiva" respecto al concepto de "Hacienda Pública" que nuestra Constitución utiliza, trasladándolas en este caso al concepto de “inversión pública”. Al respecto, sostiene dicho autor que una interpretación evolutiva del concepto de Hacienda Pública nos permitiría abarcar no sólo a las entidades que participan, en simultáneo, de las notas de "publicidad

17 Elaborado por la Intendencia y aprobado por la Junta Departamental, de conformidad con el procedimiento establecido en los artículos 222 y siguientes de la Carta.

18 Previsto en el numeral 6 del artículo 273.

19 DELPIAZZO, Carlos E. "Tránsito de la contratación administrativa a la contratación pública" en DELPIAZZO, Carlos E. (Coordinador), Nuevos aspectos de las relaciones administrativas, Montevideo, Fundación de Cultura Universitaria, 2011, p. 339.

20 El Banco República y la Universidad de la República son ejemplos de entidades estatales que han constituido fundaciones.

21 Ley de Fundaciones $\mathrm{N}^{\circ} 17.163$ de $1^{\circ}$ de setiembre de 1999 , art. 1. 
y estatalidad", sino también a aquellas que presentan una sola de dichas características, esto es, las que son públicas no estatales y las que son privadas estatales. ${ }^{22}$

Si bien el SNIP no utiliza la noción de Hacienda Pública, el razonamiento de DELPIAZZO deviene aplicable, en tanto se utiliza el concepto de inversión pública con una dimensión subjetiva amplísima, alcanzando a (i) lo público estatal, (ii) lo público no estatal y (iii) lo privado estatal. Todos los recursos manejados por entidades que ingresan en una de esas tres categorías quedan abarcados en el ámbito del SNIP, en el entendido que sus inversiones provienen de dicha hacienda.

Desde el punto de vista objetivo, el SNIP comprende la inversión pública y la transferencia de capital a terceros perceptores. ${ }^{23}$

El texto reglamentario define a la inversión pública como "la aplicación de recursos en todo tipo de bienes y actividades que incrementen el patrimonio de las instituciones alcanzadas por el artículo 24 de la Ley $N^{\circ} 18.996$, el capital físico, el capital humano y la creación de conocimiento, cuyo fin sea crear, ampliar, mejorar, modernizar, reponer o recuperar la capacidad productora de bienes o prestadora de servicios."

Este concepto de inversión abarca: (a) tanto a aquellos recursos que sean aplicados en bienes como en actividades; (b) siempre y cuando incrementen patrimonio, capital físico, capital humano o creen conocimiento; (c) la finalidad debe estar relacionada a la capacidad productora de bienes o prestadora de servicios para crearla, ampliarla, mejorarla, modernizarla, reponerla o recuperarla.

Esta definición presenta diferencias con la manejada por el TOI mencionada ut supra, en tanto supone aplicación de recursos no solo en patrimonio y activo físico, sino en capital humano y creación de conocimiento. ${ }^{24}$ Por lo tanto, la capacitación de los funcionarios de un organismo alcanzado por el SNIP debe ser considerada inversión pública, como también lo es el destinar recursos a una investigación (creación de conocimiento). El objetivo final debe ser el mismo: tener un impacto en la capacidad productora de bienes o prestadora de servicios. En la medida en que dichas actividades reportan beneficios perdurables en el tiempo, aun cuando no supongan aumento del activo físico, no estarían disociadas del concepto natural de inversión, que -como vimos- no necesariamente requiere de una manifestación en el mundo sensible.

La ley establece claramente cuál es la finalidad del SNIP: optimizar la asignación de recursos públicos con ajuste a las políticas sectoriales nacionales diseñadas por el Poder Ejecutivo. Esa finalidad deberá ser siempre la que guie el accionar de la OPP, en tanto cuando una disposición normativa atribuye una potestad jurídica y determina una finalidad, esta deviene de cumplimiento necesario para la entidad estatal. La finalidad puede definirse como el fin mediato, efecto o resultado final, a que la actividad del órgano estatal debe tender e, independientemente de que todo órgano estatal persigue el interés general, lo debe hacer en el marco de la finalidad concreta que la norma atributiva de

22 Cfr. DELPIAZZO, Carlos E. "Alcance de la noción de Hacienda Pública" en DELPIAZZO, Carlos E. (Coordinador), Comentarios al TOCAF sobre la Hacienda Pública, Montevideo, Universidad de Montevideo, 2012, p. 40.

${ }^{23}$ Artículo 4 del Decreto $\mathrm{N}^{\circ} 231 / 015$.

${ }^{24}$ El artículo 5 del Decreto $\mathrm{N}^{\circ} 231 / 015$ expresamente hace esta salvedad, al establecer que a los efectos presupuestales se mantiene vigente la definición (más acotada) del artículo 1 del TOI. 
competencia le haya indicado, en forma implícita o explícita. ${ }^{25}$ La OPP, como órgano rector del SNIP, tiene su finalidad explícitamente definida.

No caben dudas que la optimización de la asignación en los recursos públicos es una finalidad absolutamente compatible con el texto constitucional. Sin embargo, que ello se haga a partir del ajuste a las políticas sectoriales que fije el Poder Ejecutivo, resulta más cuestionable, según veremos más adelante.

\section{c. SNIP y la OPP}

La OPP es un órgano de competencia constitucionalmente abierta, según surge del artículo 230, en virtud del cual la ley puede atribuirle nuevos cometidos.

Asimismo, el SNIP resulta compatible con la competencia material que la Constitución atribuye a la OPP, en tanto órgano encargado de la planificación y los presupuestos. La idea de ordenar la inversión pública y optimizarla se vincula con ambos cometidos: con la planificación, puesto que su función es la de "ofrecer criterios para la asignación de recursos, sobre cuyas bases decidan las acciones directas del sector público y la acción del gobierno que representa el uso de los distintos instrumentos de política económica" ${ }^{26}$; y con los presupuestos, porque son la herramienta que reflejan las inversiones que harán los organismos estatales.

A lo anterior se suma, y como ya dijéramos, que la OPP es la sucesora de la CIDE, por disposición constitucional expresa, por lo que su actuación en el campo de la inversión pública la acompaña desde su propio nacimiento.

De todas formas, queda abierta la discusión en relación a si atribuirle a la OPP facultades decisorias o de administración activa, que vayan más allá del asesoramiento y la asistencia, resulta ajustado a la Carta. ${ }^{27}$

\section{d. SNIP y control ¿mérito o legalidad?}

Siempre que se habla de control es necesario determinar cuáles son los criterios a partir de los cuales se ejercerá, existiendo controles de legalidad (si la actividad se desarrolla dentro de las pautas fijadas por el ordenamiento jurídico) y de mérito (que recaen sobre la conveniencia u oportunidad de lo actuado).

El SNIP no aclara expresamente cuál es el control que se le ha asignado a la OPP. Sin embargo, a partir de la finalidad expresamente reconocida (optimización de los recursos públicos con adecuación a las políticas sectoriales que fije el Poder Ejecutivo) es razonable entender que se trata de un control de mérito, pues tal adecuación no es una razón de legitimidad.

25 Cfr. CAJARVIlle PELUfFo, Juan Pablo. Sobre Derecho Administrativo, T II, $2^{\circ}$ Ed., Montevideo, Fundación de Cultura Universitaria, 2008, pp. 25-27.

26 RUIBAL DIBELLO, Milton; LÓPEZ ROCCA, Elbio; BURSZTYN WAS, Saúl. Oficina de Planeamiento y Presupuesto, Montevideo, Amalio M. Fernández, 1972, p. 34.

27 En contra de atribuirle potestades distintas a las de asesoramiento y asistencia: CAGNONI, José Aníbal. "El despertar de largo letargo: Comisión de Planeamiento y Presupuesto" en Revista de Derecho Público, N²7, p. 120 y en "De la superioridad de la Constitución sobre la Ley" en Revista de Derecho Público, N²9, p. 62. También RUIBAL DIBELLO, Milton; LÓPEZ ROCCA, Elbio; BURSZTYN WAS, Saúl. Ob. cit., p. 71. 
Con relación a los órganos que integran el Poder Ejecutivo la regulación del SNIP no presenta a nuestro criterio objeciones de constitucionalidad, en tanto se trata de controles dentro del mismo sistema orgánico que integran y a efectos de que todos los subsistemas se alineen a las políticas sectoriales que el jerarca máximo establece. ${ }^{28}$ Constituye pues un mecanismo de unificación de la actuación de las distintas dependencias del Poder Ejecutivo, inherente a sus potestades jerárquicas.

En el caso de entes autónomos, servicios descentralizados y personas públicas no estatales no existe un vínculo de jerarquía con el Poder Ejecutivo; en consecuencia pueden -legítimamente- no seguir los lineamientos de política sectorial que aquel haya trazado. Este podrá hacer uso de sus potestades constitucionales y legales para encauzarlos, pero sin que ello suponga que la actuación de la entidad haya sido ilegítima. Por tanto, incorporar este control en las decisiones de inversión supone incidir en el mérito de lo que resuelven, a efectos de alinearlos a las políticas sectoriales.

Para el caso del Poder Judicial y los órganos constitucionales de contralor no tienen el deber de ajustarse a las políticas sectoriales del Poder Ejecutivo, por cuanto la Constitución les ha garantizado autonomía en el ejercicio de sus funciones, sin que existan controles de aquel sobre ellos, que garanticen tal alineamiento. En consecuencia, la finalidad del SNIP (optimizar los recursos con ajuste a las políticas sectoriales del Poder Ejecutivo) resulta de dudosa constitucionalidad, excepto que entendamos que la salvedad hecha en el artículo 23 (“....sin perjuicio de las autonomías y competencias constitucionales...”) supone que dicha adecuación no resulta de aplicación para estos sistemas orgánicos, lo cual requeriría postular una lectura restrictiva de la ley. Si el Poder Ejecutivo desea incidir en las decisiones de inversión de dichos sistemas orgánicos, podrá hacerlo en la instancia presupuestal y con los límites que la Constitución establece. E incluso, una vez que el presupuesto de estos organismos esté aprobado por el Parlamento, no resultará ajustado a la Constitución que se le obstaculice la autorización para ejecutarlo, al negarle el DTF. El análisis de mérito corresponde en todo caso al Poder Legislativo, quien se pronuncia mediante la ley presupuestal.

\section{e. SNIP y actos administrativos}

Un punto que genera dificultad es el de cómo resolver una eventual contienda entre el organismo que presenta el proyecto de inversión y la OPP, en caso que emitiera ésta informe desfavorable. La ley del SNIP no lo resuelve; el decreto reglamentario ofrece una solución parcial al establecer que aún sin DTF de OPP, el Poder Ejecutivo puede habilitar la ejecución de un proyecto de inversión. ${ }^{29}$

Debería en primer término analizarse si el dictamen que deniega la CT a la inversión es realmente un dictamen o un acto administrativo. ${ }^{30}$ Si fuera un dictamen, se trataría de un mero asesoramiento que no produciría efectos jurídicos y, por ende, el organismo podría seguir adelante con la inversión. Sin embargo, en la medida en que un dictamen negativo

28 Cfr. SOLER, Graciela. Ob. cit., p. 49.

29 Art. 24. Se trataría pues de una controversia en la cual el proyecto ya fue incorporado al presupuesto (pues contó con CT) y se encuentra en la etapa previa de ejecución.

30 El artículo 12 de decreto reglamentario, al referirse a la Conformidad Técnica y el Dictamen Técnico los califica expresamente de "informes". 
impide al organismo continuar con el proceso, se trata en puridad de un verdadero acto administrativo, por cuanto despliega efectos jurídicos, al constituirse en obstáculo para que aquel pueda realizar la inversión que tenía planificada. ${ }^{31}$

Responder afirmativamente en relación a la naturaleza de acto administrativo supone avanzar a la siguiente pregunta: ¿se imputa el acto administrativo al Director de la OPP o a la Comisión Directiva de OPP? Allí tendremos el primer punto para saber quien dicta la resolución sobre el recurso de revocación. ${ }^{32}$ Con respecto al recurso jerárquico, y por la naturaleza institucional de la OPP, lo resolvería la Presidencia de la República.

Sin embargo, se plantea otra complejidad, en tanto los órganos afectados por la no obtención de la CT o el DTF pueden ser de distinta naturaleza jurídica. Debería pues diferenciarse según se trate de órganos pertenecientes al Poder Ejecutivo (en cuyo caso la controversia se resuelve en aplicación de las potestades jerárquicas; sin perjuicio de plantearse el problema de si la Presidencia integra o no el Poder Ejecutivo) a los restantes (no sujetos a jerarquía de aquel), en cuyo caso sí resulta razonable la interposición de recursos administrativos.

\section{f. SNIP y presupuestos}

Cuando se trate de órganos y organismos comprendidos en el artículo 220 de la Constitución, se puede plantear el problema de la constitucionalidad de la solución: ¿Qué sucede sin un organismo comprendido en dicho artículo remite al Poder Ejecutivo un proyecto de presupuesto con proyectos de inversión que no cuentan con CT?

En relación al procedimiento regulado en el artículo 220, SARLO sostuvo que, sin perjuicio de lo inadecuado del término utilizado por la Constitución (“...modificar...”), lo cierto es que la siguiente parte de la frase no permite dudas en cuanto a que el Poder Ejecutivo sólo está facultado a promover una solución alternativa al proyecto que remita el organismo. ${ }^{33}$ Para SARLO la sistemática constitucional es clara en cuanto a que cada organismo autónomo realiza su propuesta presupuestal, cuyo único control de legalidad externo corresponde al Tribunal de Cuentas, agregando que un control de oportunidad o conveniencia debería estar previsto a texto expreso. ${ }^{34}$

La regulación legal del SNIP deviene entonces contraria a la dinámica constitucional en materia de presupuestos de los organismos comprendidos en el artículo 220 de la Constitución. Si el Poder Ejecutivo entiende que los proyectos de inversión contenidos en los presupuestos elaborados por tales organismos no se adecuan a sus políticas sectoriales, tiene la posibilidad de enviarlos al Parlamento con las modificaciones que entienda pertinentes (esto es, el proyecto original y el proyecto del Poder Ejecutivo), y será el Poder

${ }_{31}$ Es algo similar a los actos que imposibilitan o suspenden la tramitación del procedimiento, y respecto a los cuales CAJARVILLE sostiene que si hacen imposible o suspenden indefinidamente el procedimiento previo al dictado del acto final, puede ser considerado como el acto originario y recurrible. Cfr. CAJARVILLE PELUFFO, Juan Pablo. Ob cit., Tomo II, p. 251.

${ }^{32}$ Sobre la discusión en doctrina puede consultarse: RUIBAL, LÓPEZ Y BURSZTYN, p. 58-61. Sobre la Comisión de Planeamiento y Presupuesto puede verse: CAGNONI, José Anibal. Ob. cit., p. 120.

33 SARLO, Oscar. Presupuesto, justicia y contralor, Montevideo, Fundación de Cultura Universitaria, 1992, p. 94.

34 SARLO, Oscar. Ob. cit., p. 95. 
Legislativo quien dirima la controversia; ${ }^{35}$ sin embargo, contar con la CT de la OPP no debería ser un requisito para su inclusión o no en las propuestas de presupuestos que los organismos del artículo 220 remiten al Poder Ejecutivo, en tanto no es una exigencia de la Carta, y menos aun si la finalidad es controlar que se adecúen a sus políticas sectoriales.

Esto nos llevaría a sostener que el organismo podría remitir su proyecto de presupuesto con proyectos de inversión que no cuenten con el aval técnico de OPP. Sin embargo, no debemos olvidar que aun cuando pudiera considerarse inconstitucional la imposición del requisito de contar con la CT, la Ley se encuentra vigente y, en consecuencia, conseguir el dictamen favorable de OPP constituye un requisito de legalidad, que será controlado por el Tribunal de Cuentas. En consecuencia, y salvo que el organismo presente la acción de inconstitucionalidad y obtenga sentencia favorable, la CT de OPP es un requisito de legitimidad respecto a cual deberá dar cumplimiento; no hacerlo determinará la observación del Tribunal al proyecto de inversión por incumplimiento de un requisito de fuente legal.

Respecto de aquellos organismos cuyo presupuesto se rige por el artículo 221 (entes del dominio industrial y comercial), la respuesta a la cuestión del ajuste del SNIP a la Constitución deviene a nuestrojuicio diferente. Si bien en este caso la Constitución también regula el procedimiento, y una eventual diferencia entre el Ente y el Poder Ejecutivo debe ser resuelta por la Asamblea General, debe tenerse en cuenta que estos tienen "el grado de descentralización que fije la ley”, según surge del artículo 185 de la Constitución. ${ }^{36}$ En consecuencia, los artículos 23 a 25 de la Ley $\mathrm{N}^{\circ} 18.996$ deben ser considerados como una disminución del grado de descentralización de que gozan estos entes, en cuanto aumenta el control del Poder Ejecutivo en el ámbito presupuestario. Todo lo anterior será sin perjuicio de que, para el caso en que el ente no acepte las observaciones del Poder Ejecutivo, la controversia pueda ser resuelta por la Asamblea General, de acuerdo a lo dispuesto por la Constitución.

Por su parte, y para reforzar la obligatoriedad del SNIP para estos entes en la etapa de ejecución, se haincluido una disposición en los decretos que aprueban sus presupuestos, que establece la necesidad de contar con el DTF de OPP para ejecutar cualquier proyecto de inversión. ${ }^{37} \mathrm{Al}$ incorporarse al propio decreto que aprueba su presupuesto, y en la medida en que cuenta con respaldo legal en la disposición ya mencionada, no pueden existir dudas en cuenta a su obligatoriedad para los organismos del artículo 221, en la fase de ejecución.

35 Cfr. SOLER. Ob. cit., pp. 49-50.

$36 \mathrm{Al}$ respecto, CAJARVILLE sostiene que "es posible que a los instrumentos de control de fuente constitucional reseñados, conferidos al Poder Ejecutivo, se adicionen otros consagrados por ley. En el régimen constitucional vigente, los Entes Autónomos, salvo los que tengan a su cargo servicios docentes, sólo gozan del "grado de descentralización", y están por ende sometidos al control del órgano central, que la ley consagre," con la limitación de los docentes. CAJARVILLE PELUFFO, Juan Pablo. Ob. cit., Tomo I, p. 616.

37 El texto establece lo siguiente: "De acuerdo con lo dispuesto en el inciso $2^{\circ}$ numeral $3^{\circ}$ del artículo $24^{\circ}$ de la Ley $N^{\circ} 18.996$ de 7 de noviembre de 2012, ningún proyecto de inversión se ejecutará sin haber obtenido en forma previa el dictamen técnico favorable de la Oficina de Planeamiento y Presupuesto de acuerdo a las Guías y Pautas Metodológicas elaborados por el Sistema Nacional de Inversión Pública." Puede encontrarse, a vía d ejemplo, en los presupuestos recientes del Instituto Nacional de Colonización (Decreto N²9/016; art. 15); Banco Central del Uruguay (Decreto N 193/017), OSE (Decreto $N^{\circ}$ 101/017), AFE (Decreto No 73/017), ANCAP (Decreto $\left.N^{\circ} 437 / 016\right)$. 
¿Cómo se compatibiliza el SNIP con el régimen de las PPNE y de "entidades privadas de propiedad estatal"?

Con las PPNE, considerando que son creadas por ley, y de ella obtienen sus potestades y sujeciones de Derecho Público, parece razonable aceptar que la propia ley puede imponerle limitaciones, como tantas otras que ya se le han impuesto y que es, en definitiva, su nota característica. Puede ser complejo de implementar, en tanto existe una multiplicidad de formas en las cuales las PPNE aprueban sus presupuestos, la mayoría de ellas sin intervención del Poder Ejecutivo. ${ }^{38}$

En el caso de las que sean ejecutoras de políticas públicas del Poder Ejecutivo y en especial cuando sus ingresos provienen de partidas presupuestales (en carácter de verdaderas subvenciones), la constitucionalidad de la solución no merece cuestionamientos. Sin embargo, cuando se trata de otro tipo de entidades la situación puede ser más dudosa, en especial en aquellas en que ni siquiera existen representantes estatales en sus órganos jerarcas (como los Colegios Médico y Veterinario) y que se financian exclusivamente con aportes coactivos de sus propios integrantes. Deberá, en cada caso y respecto a cada PPNE, establecerse si verdaderamente existen razones de interés general que justifiquen la limitación que el SNIP supone para la disponibilidad de sus recursos, resultando harto difícil plantear una conclusión general para una categoría cada vez más heterogénea.

En relación a las entidades instrumentales, su incorporación al SNIP puede interpretarse como parte de su procedimiento de "publificación". En la medida en que forman parte de "lo estatal", la creación de controles que las alcancen no presentan mayores inconvenientes en cuanto a su juridicidad; con todo, podría sí ser cuestionable la aplicabilidad del SNIP en los casos en que el Estado no sea el único socio y participen también personas privadas no estatales. ${ }^{39}$ Con respecto a este punto, la cuestión de la constitucionalidad de la imposición de los controles del SNIP a este tipo de entidades puede fundarse, en relación al socio privado, en que cualquiera que se asocie con el Estado debe ser consciente y soportar que su actividad quede inexorablemente ligada a fondos públicos que, por definición, requieren de controles en una sociedad democrática. En consecuencia, se trata -para ese particular- de una limitación a la libertad de industria y comercio, impuesta por ley y por razones de interés general.

En el caso de los Gobiernos Departamentales puede cuestionarse que deban obtener la CT, en la medida en que la Constitución les ha garantizado una amplia autonomía financiera. De todas formas su incorporación al SNIP está pendiente de reglamentación.

${ }_{38}$ Puede ampliarse en: DÍAZ INVERSO, Rodrigo. "Los controles del Poder Ejecutivo sobre las personas públicas no estatales" en ROTONDO, Felipe (Coordinador), Control estatal sobre la entidades públicas y las instrumentales de derecho privado, Montevideo, Fundación de Cultura Universitaria, 2017, pp. 395-396 y 406-411.

39 Puede consultarse un listado de personas jurídicas privadas con capital estatal en: VÁZQUEZ, Cristina. "Entidades instrumentales y responsabilidad del Estado" en ROTONDO, Felipe (Coordinador), Estudios sobre la Administración Uruguaya, Tomo I, Montevideo, Fundación de Cultura Universitaria, 2016, pp. 127-129. 


\section{g. SNIP y el Tribunal de Cuentas}

El 16 de diciembre de 2015 el Tribunal dictó la Ordenanza Nº8, en virtud de la cual dispone que controlará el cumplimiento de las disposiciones del SNIP tanto en la etapa presupuestal (cuando el presupuesto es sometido a su consideración) ${ }^{40}$ como en la de intervención preventiva del gasto. ${ }^{41}$ En la medida en que la ley y su decreto reglamentario imponen obligaciones a los organismos alcanzados por el SNIP, el Tribunal consideró que su cumplimiento es una cuestión de legalidad que queda comprendida en su ámbito de actuación.

La ordenanza del Tribunal parece por demás adecuada, en tanto las disposiciones del SNIP conforman parte del haz de juridicidad cuyo control tiene a cargo dicho órgano, tanto en materia de presupuestos como de gastos.

\section{REFLEXIONES FINALES.-}

La inversión pública es un motor de desarrollo en nuestra economía, siendo innegable su importancia; es un instrumento de política económica insustituible en poder del Estado para incidir en la economía y poder prevenir, detener o morigerar los efectos cíclicos de aquella. Que dicha inversión se planifique y se ejecute en forma ordenada resulta ante todo un imperativo ético, en tanto constituye la utilización y gestión de recursos públicos; es, al mismo tiempo, un imperativo jurídico derivado del deber de buena administración que pesa sobre los órganos estatales.

Por lo anterior, la implementación de un sistema que tienda a orientar y ordenar los procesos de inversión pública debe ser bienvenido, como forma de optimizar y potenciar la intervención del Estado en la economía, independientemente de la forma jurídico-organizativa que utilice. También debe resaltarse como aspecto positivo, en términos de transparencia y sistematización de la información, la unificación de datos de inversión pública, que permita su agrupamiento y el seguimiento de su ejecución. Sólo con información sistematizada, transparente y de calidad es posible ejecutar y controlar políticas públicas.

Por su parte, que dicho sistema se encuentre radicado en la OPP aparece como una opción de política legislativa compartible, en tanto armoniza con el rol planificador que nuestra Carta le asigna a dicha repartición. Es una oficina que debe tener la capacidad de planificar el desarrollo del país a largo plazo y, para ello, incidir sobre el destino y la forma en que se ejecutan los fondos públicos para indispensable.

40 En el numeral 2) de la ordenanza se dispone lo siguiente: "En la etapa de intervención en materia presupuestal, se controlará que cada proyecto de inversión incluido en el presupuesto cuente con el informe de Conformidad Técnica (CT) del SNIP. A esos efectos, dichos organismos, al someter su presupuesto al control constitucional del Tribunal (Artículo 211 Literal A) presentarán la documentación que respalde la existencia de CT de cada programa o proyecto de inversión SNIP incluido en dicho presupuesto".

41 En el numeral 3) de la ordenanza se dispone lo siguiente: "En oportunidad de someter a la intervención preventiva cualquier gasto asociado a proyectos de inversión SNIP, los organismos presentarán, junto a la documentación referida al proyecto presupuestal y al gasto, la documentación que verifique la validez del DTF, emitida por el SNIP. Cuando se trate de un gasto asociado a un programa de inversión SNIP, los organismos remitirán la identificación tanto del programa como de los proyectos que originan el gasto para permitir la verificación de que cada uno de estos posea el DTF". 
Sin perjuicio de lo anterior, existen ciertos aspectos de la implementación del SNIP que dejan dudas en relación a su constitucionalidad, en especial en relación al sistema de autonomías de distinto tipo que nuestra Constitución consagra.

\section{Bibliografía consultada.}

BLANCO, Andrés. Estudios críticos sobre Finanzas Públicas y Derecho Tributario. Montevideo, Fundación de Cultura Universitaria, 2013.

CAGNONI, José Aníbal. "El despertar de largo letargo: Comisión de Planeamiento y Presupuesto" en Revista de Derecho Público, N²7, pp. 119-120.

CAGNONI, José Aníbal. “De la superioridad de la Constitución sobre la Ley” en Revista de Derecho Público, $\mathrm{N}^{\circ} 29$, p. 59-67.

CAJARVILLE PELUFFO, Juan Pablo. Sobre Derecho Administrativo, T. I, $2^{\circ}$ Ed. Montevideo, Fundación de Cultura Universitaria, 2008.

CAJARVILLE PELUFFO, Juan Pablo. Sobre Derecho Administrativo, T. II, $2^{\circ}$ Ed. Montevideo, Fundación de Cultura Universitaria, 2008.

DELPIAZZO, Carlos E. "Tránsito de la contratación administrativa a la contratación pública" en DELPIAZZO, Carlos E. (Coordinador), Nuevos aspectos de las relaciones administrativas, Montevideo, Fundación de Cultura Universitaria, 2011, pp. 337-352.

DELPIAZZO, Carlos E. "Régimen de inversiones" en DELPIAZZO, Carlos E. (Coordinador), Comentarios al TOCAF sobre la Hacienda Pública, Montevideo, Universidad de Montevideo, 2012, pp. 99-109.

DELPIAZZO, Carlos E. "Alcance de la noción de Hacienda Pública" en DELPIAZZO, Carlos E. (Coordinador), Comentarios al TOCAF sobre la Hacienda Pública, Montevideo: Universidad de Montevideo, 2012, pp. 23-41.

DELPIAZZO, Carlos E. "Promoción y captación de la inversión privada en el sector público" en ROTONDO, Felipe (Coordinador), Regulación de la actividad privada, Montevideo, Fundación de Cultura Universitaria, 2015, pp. 109-125.

DÍAZ INVERSO, Rodrigo. "Los controles del Poder Ejecutivo sobre las personas públicas no estatales" en ROTONDO, Felipe (Coordinador), Control estatal sobre la entidades públicas y las instrumentales de derecho privado, Montevideo, Fundación de Cultura Universitaria, 2017, pp. 384-411.

RUIBAL DIBELLO, Milton; LÓPEZ ROCCA, Elbio; BURSZTYN WAS, Saúl. Oficina de Planeamiento y Presupuesto, Montevideo, Amalio M. Fernández, 1972.

SARLO, Oscar. Presupuesto, justicia y contralor, Montevideo, Fundación de Cultura Universitaria, 1992.

SOLER, Graciela. "Contralor de organismos estatales y no estatales a través del SNIP" en ROTONDO, Felipe (Coordinador), Control estatal sobre la entidades públicas y las instrumentales de derecho privado, Montevideo, Fundación de Cultura Universitaria, 2017, pp. 41-51.

VÁZQUEZ, Cristina. "Entidades instrumentales y responsabilidad del Estado" en ROTONDO, Felipe (Coordinador), Estudios sobre la Administración Uruguaya, Tomo I, Montevideo, Fundación de Cultura Universitaria, 2016, pp. 107-131.

VIDAL, Martha. La gestión financiera del Estado. Montevideo, Fundación de Cultura Universitaria, 2015.

Fecha de recepción: 4 febrero 2019.

Fecha de aceptación: 14 de marzo2019. 